\title{
1 Landscape connectivity alters the evolution of density- 2 dependent dispersal during pushed range expansions
}

3 Maxime Dahirel ${ }^{1}$, Aline Bertin ${ }^{1}$, Vincent Calcagno ${ }^{1},{\text { Camille } \text { Duraj }^{1} \text {, Simon Fellous }}^{2}$, Géraldine

4 Groussier $^{1}$, Eric Lombaert ${ }^{1}$, Ludovic Mailleret ${ }^{1,3}$, Anaël Marchand ${ }^{1}$, Elodie Vercken ${ }^{1}$

$5{ }^{1}$ Université Côte d'Azur, INRAE, CNRS, ISA, France

$6 \quad{ }^{2}$ INRAE, Univ. Montpellier, CIRAD, IRD, Montpellier SupAgro, CBGP, France

7 3 Université Côte d'Azur, INRIA, INRAE, CNRS, Sorbonne Université, BIOCORE, Sophia Antipolis,

8 France

9 corresponding author: MD, maxime.dahirel@yahoo.fr 


\section{Abstract}

12 As human influence reshapes communities worldwide, many species expand or shift their 13 ranges as a result, with extensive consequences across levels of biological organization. Range

14 expansions can be ranked on a continuum going from pulled dynamics, in which low-density 15 edge populations provide the "fuel" for the advance, to pushed dynamics in which high-density 16 rear populations "push" the expansion forward. While theory suggests that evolution during 17 range expansions could lead pushed expansions to become pulled with time, empirical 18 comparisons of phenotypic divergence in pushed vs. pulled contexts are lacking. In a previous 19 experiment using Trichogramma brassicae wasps as a model, we showed that expansions were 20 more pushed when connectivity was lower. Here we used descendants from these experimental 21 landscapes to look at how the range expansion process and connectivity interact to shape 22 phenotypic evolution. Interestingly, we found no clear and consistent phenotypic shifts, 23 whether along expansion gradients or between reference and low connectivity replicates, when 24 we focused on low-density trait expression. However, we found evidence of changes in density25 dependence, in particular regarding dispersal: populations went from positive to negative 26 density-dependent dispersal at the expansion edge, but only when connectivity was high. As

27 positive density-dependent dispersal leads to pushed expansions, our results confirm 28 predictions that evolution during range expansions may lead pushed expansions to become 29 pulled, but add nuance by showing landscape conditions may slow down or cancel this process.

30 This shows we need to jointly consider evolution and landscape context to accurately predict 31 range expansion dynamics and their consequences.

32 Keywords: biological invasions; context-dependent dispersal; experimental evolution; habitat 33 fragmentation; spatial sorting; Trichogramma 


\section{Introduction}

36 Many species distribution ranges are currently shrinking, shifting or expanding as a direct or

37 indirect result of human influence. Climate-tracking species and invasive species, in particular,

38 are the focus of research efforts aiming to describe and understand their dynamics (Chuang \&

39 Peterson, 2016; Lenoir et al., 2020; Renault et al., 2018). Within-species trait variability has

40 reverberating impacts across organisation levels, from populations to ecosystem functioning

41 (Des Roches et al., 2018; Jacob et al., 2019; Little et al., 2019; Raffard et al., 2019; Violle et al.,

42 2012). Thus, knowing how phenotypes are redistributed in space during range expansions and

43 range shifts is likely key to understand the ecological and evolutionary dynamics at play in the

44 resulting communities (Cote et al., 2017; Miller et al., 2020; Renault et al., 2018).

45 The speed at which a species' range expands in space is, ultimately, a function of both 46 population growth and dispersal (Lewis et al., 2016). As populations/species differ qualitatively

47 in their growth and dispersal functions (Fronhofer et al., 2018; Gregory et al., 2010; Harman et

48 al., 2020; Sibly \& Hone, 2002), due to intrinsic and/or environmental drivers, we can expect

49 them to differ in the way they advance during range expansions too. Building on the framework

50 of reaction-diffusion equations, one can discriminate between "pushed" and "pulled"

51 expansions (Lewis et al., 2016; Stokes, 1976), although it may be more accurate to think of it as

52 a continuum of "pushiness" (Birzu et al., 2018). Pulled expansions are the type often implied "by

53 default" in many ecological studies (see e.g. Deforet et al., 2019; Weiss-Lehman et al., 2017).

54 Pulled expansions assume dispersal and growth are either constant or maximal at the lowest

55 densities. This leads to expansions being "pulled" forward by the few individuals at the low-

56 density, recently populated edge (Lewis et al., 2016; Stokes, 1976). However, in many species,

57 dispersal is actually more likely at high densities, as a way to escape increased competition

58 (Harman et al., 2020; Matthysen, 2005). Additionally, populations can exhibit Allee effects (Allee

59 \& Bowen, 1932; Courchamp et al., 2008), i.e. have their growth rate decrease at lower densities.

60 In both cases, this leads to the product of per capita growth and dispersal being highest at

61 intermediate or high densities; these expansions are thus "pushed" by older populations that

62 have reached these densities, instead of being primarily driven by low-density edge populations. 
63 Individuals founding new populations at the leading edge of an expansion are likely a non-

64 random sample of available phenotypes, because individuals with traits facilitating spread are

65 more likely to reach these new habitats in the first place. If these individual differences are

66 heritable, then these traits can evolve during expansion, as phenotypes facilitating spread

67 accumulate at the expansion edge with time (Cwynar \& MacDonald, 1987; Phillips \& Perkins,

68 2019; Shine et al., 2011). Evolution of increased dispersal ability in leading-edge populations is

69 now well documented, both in experimental and natural contexts (Chuang \& Peterson, 2016;

70 Deforet et al., 2019; Fronhofer et al., 2017; Weiss-Lehman et al., 2017). In addition, relaxed

71 density-dependence at the lower-density edge can select for faster life-history, e.g. higher

72 fecundity (Burton et al., 2010; Van Petegem et al., 2018). Both models and reshuffling

73 experiments (where individuals' locations are regularly randomized to stop spatial evolution)

74 have demonstrated how these evolutionary changes can accelerate expansions (Perkins et al.,

75 2013; Schreiber \& Beckman, 2020; J. M. Travis \& Dytham, 2002; Van Petegem et al., 2018;

76 Weiss-Lehman et al., 2017). However, summarizing empirical studies also shows that these

77 directional shifts in population growth, dispersal or associated traits do not always happen

78 during range expansions (Chuang \& Peterson, 2016; Merwin, 2019; Van Petegem et al., 2018;

79 Wolz et al., 2020). We need a better understanding of what determines whether or not this

80 evolution will occur, and whether it will affect growth traits or dispersal traits, if we want to

81 successfully predict (and potentially manage) the ecological and evolutionary dynamics of range

82 expansions or shifts.

83 Where an expansion sits on the pushed-pulled continuum can have consequences on its 84 evolutionary dynamics: for instance, (more) pushed expansions should conserve more genetic 85 diversity (Birzu et al., 2018, 2019; Roques et al., 2012). While this effect of expansion type on 86 neutral evolution has been confirmed experimentally (e.g. Gandhi et al., 2019), the possibility 87 that pushed and pulled expansions may also differ in their adaptive evolutionary dynamics has 88 remained almost completely unstudied so far (Birzu et al., 2019). Exploring this is in our opinion 89 the next step in pushed expansion studies, given the distinction between pushed and pulled 90 expansions rests, at its core, on traits (dispersal and fecundity) we now know can evolve during 91 range expansions. Moreover, there is evidence that evolution during range expansion can lead 
92 to changes in not only average dispersal between core and edge populations, but also in the

93 density dependence of dispersal, i.e. precisely one of the characteristics that determine

94 whether an expansion is pushed or not. While studies (theoretical and empirical) are few, they

95 hint that evolution at range edges may lead pushed expansions to become pulled (Erm \&

96 Phillips, 2020), as they show an initial positive density-dependence in growth or dispersal is lost

97 during expansion (Erm \& Phillips, 2020; Fronhofer et al., 2017; Travis et al., 2009; Weiss-Lehman

98 et al., 2017; but see Mishra et al., 2020).

99 In the current context of habitat loss and fragmentation, several studies have set to explore how 100 habitat connectivity can affect range expansion speeds and/or the evolution of dispersal and 101 other traits during range expansions (Gralka \& Hallatschek, 2019; Hunter et al., 2021; Lutscher \& 102 Musgrave, 2017; Pachepsky \& Levine, 2011; Urquhart \& Williams, 2021; Williams, Snyder, et al., 103 2016; Williams, Kendall, et al., 2016; Williams \& Levine, 2018). For instance, using experimental 104 expansions, Williams et al. (2016) showed that evolution had stronger effects on range 105 expansion speeds in patchier landscapes where connectivity was lower (or, conversely, that 106 evolution dampened the negative effects of low connectivity on speed). Experiments and 107 models show that less connected landscapes also select more strongly for large 108 individuals/more competitive individuals than continuous landscapes during expansions, an 109 indication that evolution at expanding range edges can itself be shaped by landscape 110 connectivity (Williams, Snyder, et al., 2016; Williams, Kendall, et al., 2016). Williams and Levine 111 (2018) showed that the effects of density-dependence on expansion speed could be of the same 112 magnitude than those of connectivity, matching theoretical predictions made earlier (Pachepsky 113 \& Levine, 2011). However, this study used negative density-dependent dispersal, and as such we 114 cannot directly transpose its results to the study of pushed expansions. In addition, all these 115 studies either focused on a simple, density-independent dispersal trait or, when they did 116 account for density-dependent dispersal, ignored the effects of evolution. As a result, key 117 questions remain, that are important for our ability to successfully predict expansion dynamics: 118 how does connectivity shape the evolution of density-dependent dispersal during expansions? 119 And do connectivity-induced differences in selection pressures influence the stability of an 120 expansion type (pushed or pulled) through time (Birzu et al., 2019; Erm \& Phillips, 2020)? 
121 Here we revisit a previous study of experimental range expansions using Trichogramma 122 parasitic wasps as a model (Dahirel et al., 2021), in which we showed that reducing landscape 123 connectivity led to increased "pushiness." We this time examine the phenotypic changes that 124 have occurred in space and time depending on the type of expansion. We first ask whether 125 body size, a trait that is linked to fitness in Trichogramma (Durocher-Granger et al., 2011), 126 differs between core and edge populations and across connectivity treatments. We then

127 conduct a common-garden experiment, using the descendants of the expansion experiments, to 128 study whether different range expansion contexts led to contrasted evolutionary changes in 129 traits directly linked to spread, namely dispersal, activity and reproductive success, with special 130 attention to changes in density-dependence in part of the experiments.

\section{Methods}

\section{Study species and range expansion experiment}

133 This experimental protocol for the expansions is described in detail in a previous article (Dahirel 134 et al., 2021); we here summarise its most relevant aspects.

135 Trichogramma wasps are small (body length $\approx 0.5 \mathrm{~mm}$ when adult) egg parasitoids that are 136 relatively easy to maintain on standardised resources in the lab. We used three laboratory 137 "strains" of Trichogramma brassicae Bezdenko, 1968 (Hymenoptera: Trichogrammatidae) for 138 our experiment (Fig. 1A). Each strain was obtained by mixing three pre-existing isoline 139 populations using Fellous et al. (2014)'s protocol to ensure similar genetic representation of the 140 isolines in the final mixes. Isolines were themselves derived from individuals collected in 141 different sites across western Europe in 2013. The three resulting mixed strains had broadly 142 similar levels of genetic diversity at the start of the experiment, with expected heterozygosity 143 based on 19 microsatellite loci in the 0.3-0.4 range (Dahirel et al., 2021). They were raised using 144 irradiated eggs of the Mediterranean flour moth Ephestia kuehniella Zeller 1879 (Lepidoptera: 145 Pyralidae) as a substitution host (St-Onge et al., 2014). 
146 We monitored T. brassicae spread in 24 experimental linear landscapes (8 per genetic strain) for

14714 non-overlapping generations (Generations $0-13$, with initially released adults counted as

148 Generation 0, and the experiment stopped at the emergence of Generation 13 adults).

149 Landscapes were made of plastic vials (10 cm height, $5 \mathrm{~cm}$ diameter) connected to their nearest

150 neighbours by flexible tubes (internal diameter $5 \mathrm{~mm}$ ). In half of the replicate landscapes,

151 patches were connected by three $20 \mathrm{~cm}$ long tubes ("reference" connectivity). In the other half,

152 connectivity was reduced and patches were only connected by one longer $(40 \mathrm{~cm})$ tube (Fig.

153 1B). Patches contained approximately 450 Ephestia eggs, on paper strips to facilitate handling,

154 renewed every generation at adult emergence. We started landscapes by placing $\approx 300$ unsexed

155 adult wasps in one extremity patch (expansion was only possible in one direction), a number

156 close to the expected equilibrium population size in such a system (Morel-Journel et al., 2016).

157 Each generation, adult individuals were allowed to disperse, mate and lay eggs for 48 hours

158 before they were removed. The landscapes with reduced connectivity had on average more

159 pushed dynamics than the "reference" ones, drawing on both direct (genetic) and indirect

160 arguments (Dahirel et al., 2021). The average expansion speed was similar between the two

161 connectivity treatments (Figure 1C, Dahirel et al., 2021). Experimental landscapes, as well as

162 subsequent experiments described below, were kept under controlled conditions $\left(23^{\circ} \mathrm{C}, 70 \%\right.$

163 relative humidity, $16: 8 \mathrm{~L}: \mathrm{D})$.
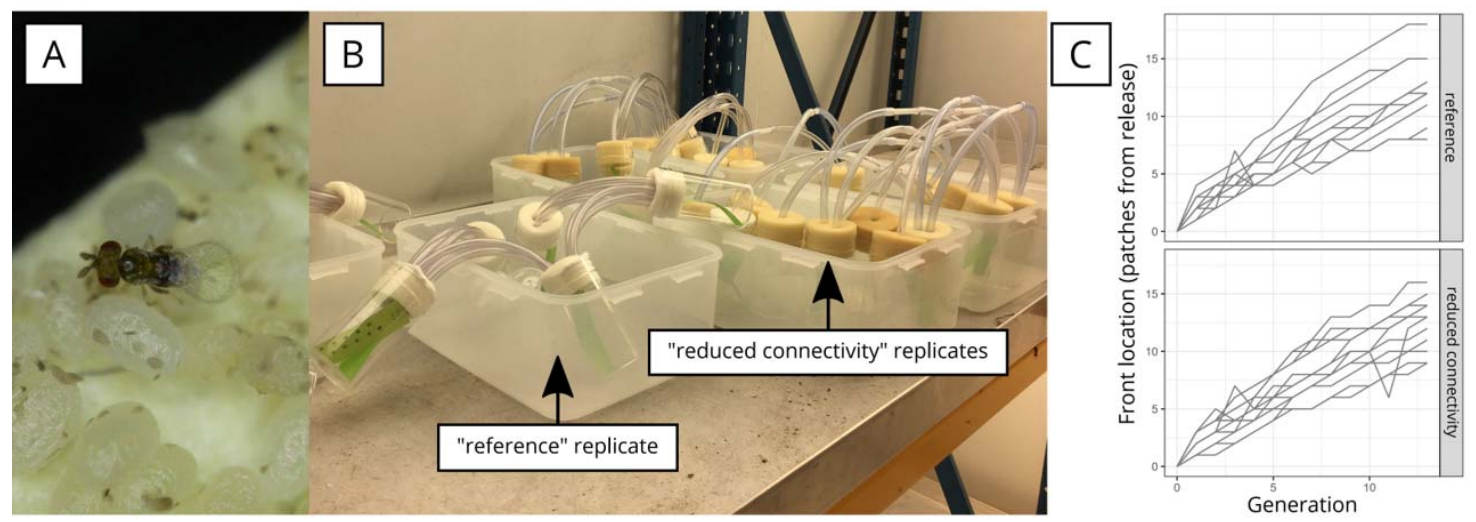

165 Figure 1 A: Trichogramma brassicae on Ephestia kuehniella eggs (picture by Géraldine 166 Groussier). B: replicate landscapes used in the range expansion experiment. Picture (by Aline 167 Bertin) shows both reference landscapes (patches connected by three $20 \mathrm{~cm}$ tubes) and 168 "reduced connectivity" landscapes (patches connected by one $40 \mathrm{~cm}$ tube). Clusters of host 


\section{Phenotypic measurements}

172 For our analysis of trait change, we focused on descendants of individuals born towards the end 173 of the experiment in "core" patches (here, the release patches or their immediate neighbours, $x$

$174=0$ or 1 ) or in the corresponding "edge" patches (i.e. the farthest populated patch in a 175 landscape at the time of sampling, or the farthest two if there were not enough individuals in

176 the farthest one). We compared them to wasps from the "stock" populations initially used to

177 start the experimental expanding landscapes. Note that mentions of " $X^{\text {th }}$ generation" wasps

178 below indicate the number of generations of experimental landscape expansion before 179 sampling/ transfer to common garden conditions. For some traits (short-term movement, and

180 fecundity and dispersal during the density-independent tests), data was also collected on one or 181 two intermediate generations. For consistency and simplicity, we only analysed (and described 182 below) the latest tested generation for each trait, but made available all data, including 183 intermediate samples (Data availability). 
bioRxiv preprint doi: https://doi.org/10.1101/2021.03.03.433752; this version posted August 23, 2021. The copyright holder for this preprint (which was not certified by peer review) is the author/funder, who has granted bioRxiv a license to display the preprint in perpetuity. It is made available under aCC-BY 4.0 International license.
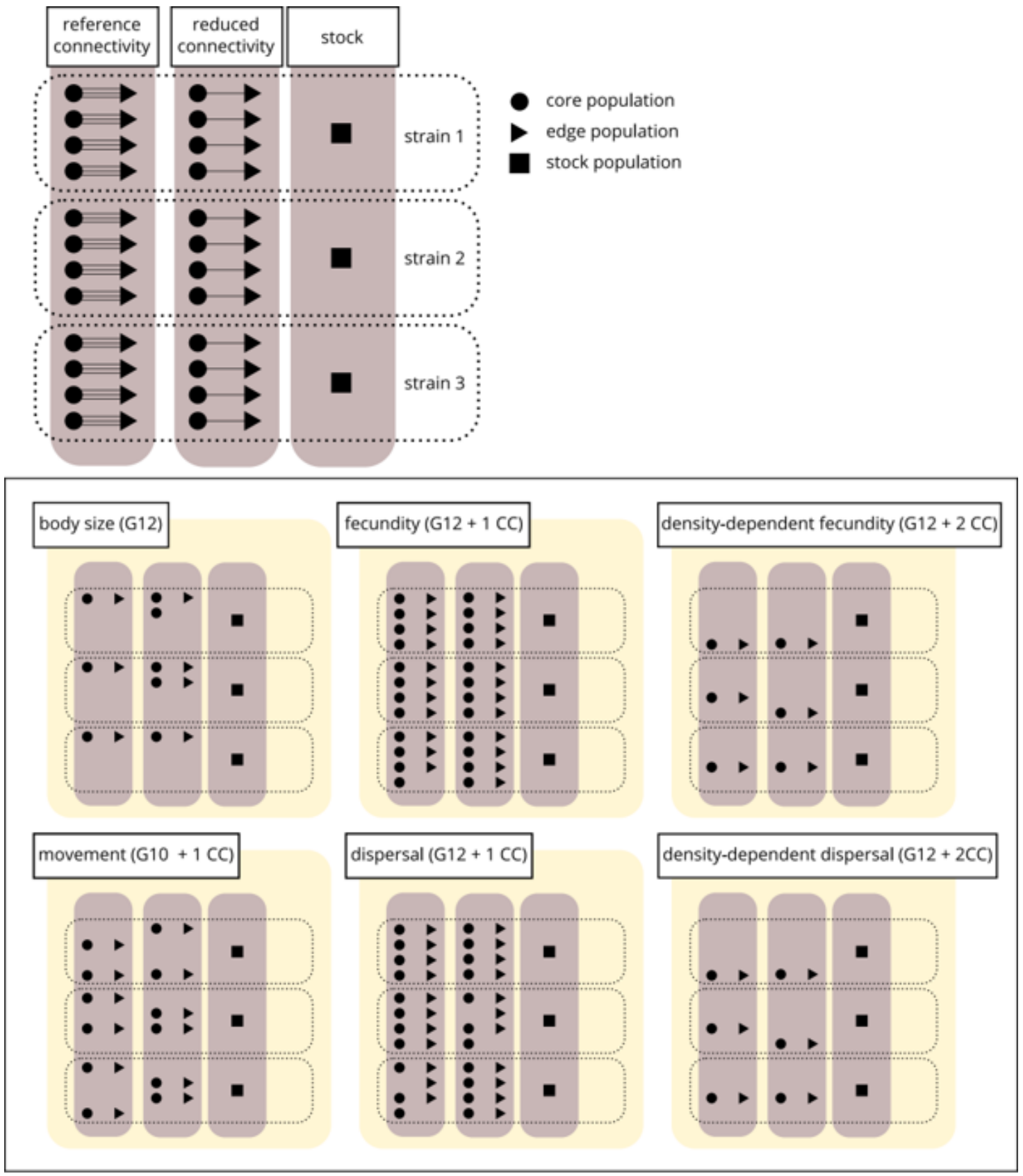

185 Figure 2 Top: summary of the experimental populations available to sample. Core and edge

186 populations from 24 experimental landscapes (split in two connectivity treatments and three

187 "strains") were available, along with the corresponding stock populations. Bottom: distribution

188 of the populations actually sampled for each phenotypic trait. The generation at which wasps

189 were taken from the experimental landscapes (+ the number of common garden generation 190 _ CC_ before testing) is indicated in parentheses besides the name of each trait. 


\section{Wasp size}

192 To determine whether landscape connectivity and expansion had an effect on body size, we

193 selected female wasps from the stock populations, and compared them to $12^{\text {th }}$ generation

194 females from the experimental landscapes. Due to logistical constraints, the latter were

195 selected in 8 edge-core pairs of populations (see Fig. 2 for how they were distributed among

196 landscape treatments and strains). Adding the three stock populations, and accounting for the

197 fact one edge-core pair was only sampled in the core due to limited numbers in the edge

198 population, we measured 316 (91 to 116 per strain) wasps in 18 populations (mean \pm SD: $17.6 \pm$

1994.0 wasps per population).

200 Wasps were kept in 70\% ethanol before phenotypic measurements. We used hind tibia length

201 (in $\mu \mathrm{m}$ ) as a body size proxy (e.g. Durocher-Granger et al., 2011). We used a Zeiss Axiolmager Z1 202 microscope equipped with a 40x/0.75 objective to photograph tibias after dissection. Images 203 were managed and measurements done using the OMERO platform (Allan et al., 2012). Wasps 204 were measured by two independent observers; inter-observer agreement was good but not

205 perfect $(r=0.93)$. We thus decided to use a hierarchical approach to explicitly include 206 measurement error in-model (see Statistical analysis below) rather than averaging observations

207 before fitting.

\section{Short-term movement}

209 To study differences in short-term movement between treatments and between core and edge 210 patches, we analysed F1 offspring of $10^{\text {th }}$ generation wasps, and compared them to each other 211 and to wasps from the stock populations. To control for population density (and other) 212 variations among landscapes, we used a common-garden protocol: wasps removed from their 213 natal landscapes after the egg-laying phase were allowed to lay eggs on new host egg strips for $21448 \mathrm{~h}$ (with $\approx 20$ females per $\approx 450$ host eggs, i.e. low density conditions). Emerging offspring 215 (unsorted by sex) were placed in an empty and lit $15 \times 19 \mathrm{~cm}$ rectangular arena, $2 \mathrm{~cm}$ high, 216 sealed above and below with a glass sheet. Groups of 15.8 individuals on average (SD: 3.3) were 217 introduced per replicate trial, and their movements filmed for five minutes. To reduce 218 behavioural changes at the edge of the arenas, and their effect on our metrics, we only tracked 
219 individuals within a central $7 \times 11 \mathrm{~cm}$ area, and the outer parts of the arena were kept in the dark 220 to discourage individuals from approaching the edges. We studied 27 populations (core and 221 edge from 12 of the 24 experimental landscapes + the three stock populations, see Fig. 2), with 2228 replicate trials per stock population, and 16 replicate trials for each of the remaining 223 populations (except one where this was 15), for a total of 119 replicate groups. Video files were 224 analysed using Ctrax (Branson et al., 2009) for tracking and the trajr R package (McLean \& 225 Volponi, 2018) for computation of movement statistics from trajectories. Most individuals were 226 not tracked continuously for the entire five minutes due to either leaving the filmed area or the 227 loss of individual identity information. As a result, output data were in the form of a series of

228 "tracklets" (i.e. any continuous sub-track longer than 2 seconds), that could not be assigned to a 229 specific individual, only to a specific replicate trial. We therefore first computed metrics at the 230 tracklet level, and then averaged them, weighted by tracklet duration, to generate replicate231 level metrics. We used the proportion of total tracked time individuals were active, the average 232 speed and the average sinuosity (Benhamou, 2004). All three movement metrics responded 233 similarly to the experimental protocol; for simplicity, we only present and discuss results from 234 the "proportion of time active" metric here, and models for the other metrics are included in 235 the associated analysis code (see Data availability).

\section{Effective dispersal}

237 F1 offspring of $12^{\text {th }}$ generation wasps (reared in a low-density common-garden setting as 238 described above) were used to evaluate dispersal differences between treatments. We placed 239 groups of 50 unsexed newly emerged wasps in a departure vial connected to an arrival vial by 240 one $40 \mathrm{~cm}$ flexible tube (i.e. reduced connectivity conditions). Both vials contained 90 host eggs. 241 We tested 47 populations (core and edge populations from all 24 experimental landscapes, 242 excluding four populations, plus the three stock populations; see Fig. 2), with two replicates per 243 "experimental landscape population" and 4 replicates per "stock population," for a total of 100 244 replicates $(44 \times 2+3 \times 4)$. One of these replicates was lost, so the final number was 99 245 replicates. We let wasps in vials for 24h, removed them, then waited 7 days and counted 246 darkened host eggs (an indication of successful parasitoid development). We used the proportion of parasitized eggs found in the arrival patches, relative to the total parasitized eggs 
248 in a replicate (departure and arrival patches), as our measure of dispersal rate. As such, it is 249 important to note it is not a measure of the percentage of individuals that dispersed (as 250 dispersers and residents may differ in sex-ratio, fecundity, competitive ability and survival, 251 Ronce \& Clobert, 2012), but rather a context-specific measure of effective dispersal or gene 252 flow. This experiment is therefore complementary from short-term movement experiments (see 253 above), as while the former experiment allows us to examine how connectivity and expansion 254 influence individuals' movement behaviour, this dispersal experiment allow us to examine their 255 net effect on all three phases of dispersal together (emigration probability, 256 movement/transience, settlement).

\section{$257 \quad$ Fecundity}

258 We placed newly emerged and presumably mated females (obtained at the same time and in 259 the same way as the ones used to measure dispersal) individually in vials containing 90 host 260 eggs, and let them lay eggs for $24 \mathrm{~h}$. We then counted the number of darkened host eggs after 7 261 days as our measure of reproductive success. Because superparasitism (more than one egg per 262 host) frequently happens in Trichogramma wasps (Corrigan et al., 1995), this is not a measure of 263 eggs produced stricto sensu, but rather a metric of reproductive success (in most cases, a single 264 adult emerges per host, even when superparasitism occurs; Corrigan et al., 1995). A total of 492 265 F1 females coming from 50 populations were used, (core and edge from all 24 experimental 266 landscapes_excluding one edge population due to low sample size_ + the three stock 267 populations, see Fig. 2) with 9.8 individuals per population on average (SD: 3.3 ).

\section{Density-dependent dispersal and fecundity}

269 F2 descendants of the $12^{\text {th }}$ generation to emerge from experimental landscapes (and from a 270 new set of stock population wasps) were subjected to the same dispersal and reproduction 271 experiments as F1 wasps, with the difference that developmental density conditions before the 272 experiments were this time manipulated. For these experiments, due to logistic constraints, we 273 studied wasps coming from each of the three stock populations and one randomly selected 274 landscape per connectivity $\times$ genetic strain combination (Fig. 2). High-density wasps were 275 obtained by placing $\approx 90$ F1 parasitized eggs close to maturity with $\approx 90$ fresh host eggs; this in 
276 effect mimics the conditions in core patches during the expansions, with populations at carrying 277 capacity and a 1 to 1 replacement of host eggs from one generation to the next. Low-density 278 wasps were obtained by placing $\approx 90$ parasitized eggs with $\approx 450$ fresh hosts; these conditions 279 are closer to the conditions experienced at the range edge. Higher densities likely led to higher 280 superparasitism and higher within-host competition during early development (Corrigan et al., 281 1995; Durocher-Granger et al., 2011). 341 F2 females were tested in total for the reproductive 282 success experiment ( $N=19$ or 20 per density level for each of the three stock populations, while 2839.3 females were tested on average for the other population $\times$ density combinations (SD: 1.7)). 284 For the dispersal experiment, we used 72 groups of 50 wasps, with 4 replicates per stock 285 population $\times$ density ( 4 replicates $\times 2$ densities $\times 3$ strains $=24$ ), and 2 replicates per remaining 286 population $\times$ density combination $(2$ replicates $\times 2$ densities $\times 2$ locations_core/edge_ $\times 2$ 287 connectivity treatments $\times 3$ strains $=48$ ).

\section{Statistical analyses}

289 Analyses were done using $R$, versions 4.0.4 and 4.1.0 (R Core Team, 2021). We analysed data in 290 a Bayesian framework using the brms R package (Bürkner, 2017) as a frontend for the Stan 291 language (Carpenter et al., 2017). We mostly relied on the tidybayes (Kay, 2019), bayesplot 292 (Gabry et al., 2019), patchwork (Pedersen, 2019) packages, and on the tidyverse suite of 293 packages (Wickham et al., 2019), for data preparation, model diagnostics and plotting. We ran 294 four Markov chains per model; the number of iterations per chain was model-dependent (but 295 always $\geq 2000$ after excluding warmup iterations), and set to be large enough to ensure 296 convergence $(\hat{R} \leq 1.01)$ and satisfactory effective sample sizes (both bulk- and tail-effective 297 sample sizes sensu Vehtari et al., 2020 > 1000). When posteriors are summarised, all 298 credible/compatibility intervals given are highest posterior density intervals. Priors were chosen 299 to be weakly informative and mostly follow suggestions by McElreath (2020); they are described 300 in detail in Supplementary Material S1, along with a formal description of each model.

301 We used (generalized) linear mixed models to analyse how phenotypic traits (size, short-term 302 movement, reproductive success and effective dispersal) varied between connectivity 303 treatment $\times$ location combinations (five levels). We used random effects (random intercepts) of 
304 genetic strain, experimental landscape nested in strain, and source location (stock, edge or core 305 patch) nested in landscape to account for phylogenetic relatedness/ shared ancestry among 306 populations (Clutton-Brock \& Harvey, 1977; Hadfield \& Nakagawa, 2010).

307 - We used a Gaussian model for size, with tibia length (centred and scaled to unit 1 SD) as the response. In addition to the fixed effect of connectivity $\times$ location and the "phylogenetic" random effects described above, and because individuals were measured twice, this model included a random effect of individual identity, allowing us to split (within-population) individual variation from (residual) observation error.

- We analysed reproduction data (number of eggs successfully parasitized) using zeroinflated negative binomial models, as initial analyses revealed zero-inflation. The submodels for the probability of excess zeroes $p$ (i.e. reproductive failure) and for the number of eggs otherwise $(\lambda)$ both included effects of phylogeny and connectivity $x$ location. For simplicity, we do not discuss in the Results section the two submodels separately, but only the overall posterior average fecundities $(1-p) \times \lambda$. The densitydependent experiment was analysed using a very similar model, with added fixed effects of density and density $\times$ connectivity $\times$ location interactions.

- $\quad$ Finally, we analysed effective dispersal rates using binomial models. As for fecundity, models included effects of phylogeny and connectivity $\times$ location (+ density and density $\times$ connectivity $\times$ location effects for the density-dependent experiment). Initial models presented some evidence of overdispersion. This was accounted for by adding the total number of eggs laid (centred and scaled to unit 1 SD) as a covariate: while it may indicate a dispersal-fecundity syndrome, a positive link between effective dispersal and total fecundity is also very likely to arise "artificially" in our setup simply because once the departure patch is saturated, individuals can only successfully reproduce if they disperse. Note that in Trichogramma, we expect a priori such saturation to appear well below the nominal limit based on host number, due to competition (Dahirel et al., 2021; 

change if we do not control for the total number of eggs laid.

\section{Results}

335 Average tibia length did not differ meaningfully between connectivity treatments and locations

336 (Fig. 3, see Supplementary Figure S.2.1 for pairwise comparisons).

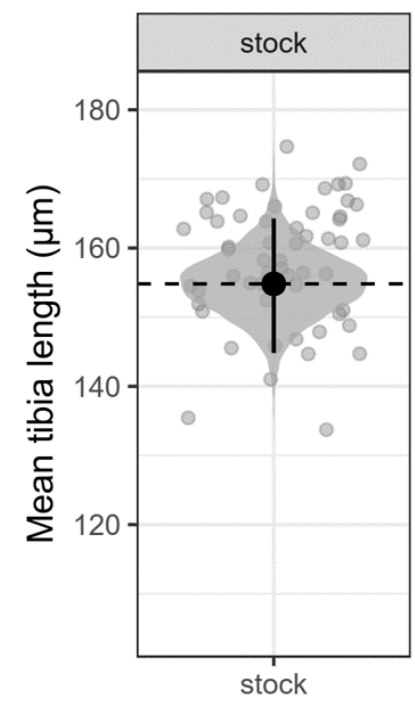

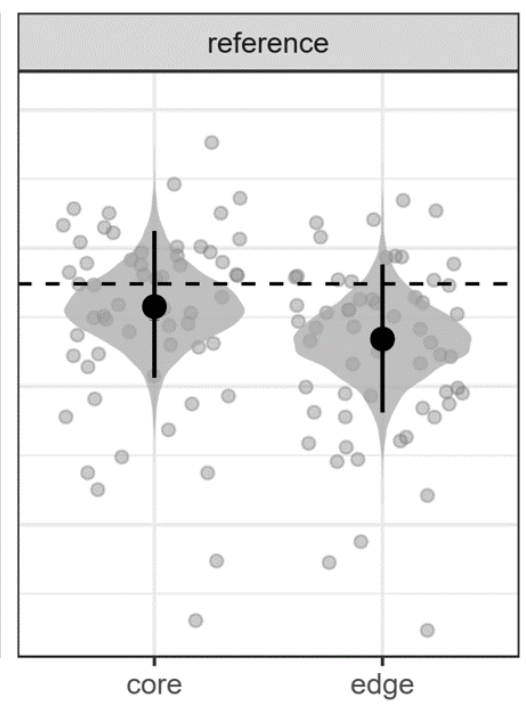

Experimental context

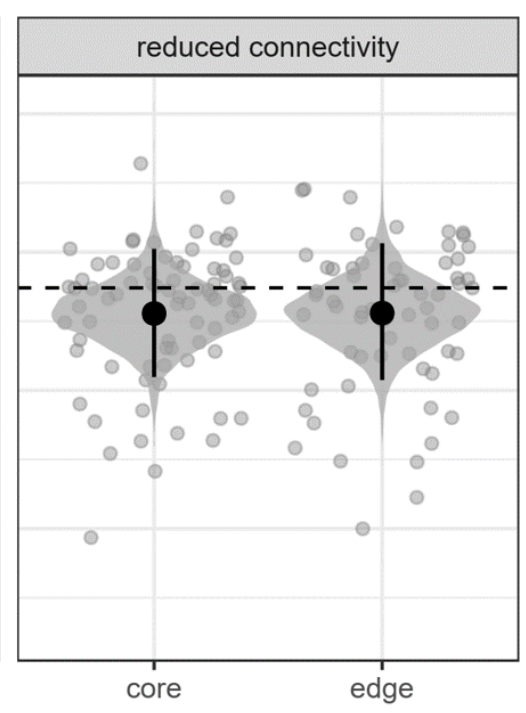

Figure 3. Posterior distribution of mean tibia length (proxy of body size); black dots and

339 segments: posterior means and 95\% credible intervals. Grey dots: individual observed values

340 (average of the two observers' measures). The horizontal dashed line marks the posterior mean

341 for the stocks. See Supplementary Figure S.2.1 for posterior pairwise comparisons.

342 We found no evidence that short-term activity had evolved during our experiments (Fig. 4, 343 Supplementary Figure S.2.2). Individuals were on average active $53 \%$ of the time they were 344 filmed, regardless of connectivity treatments and location (grand mean; 95\% Cl: [37\%; 67\%]). 

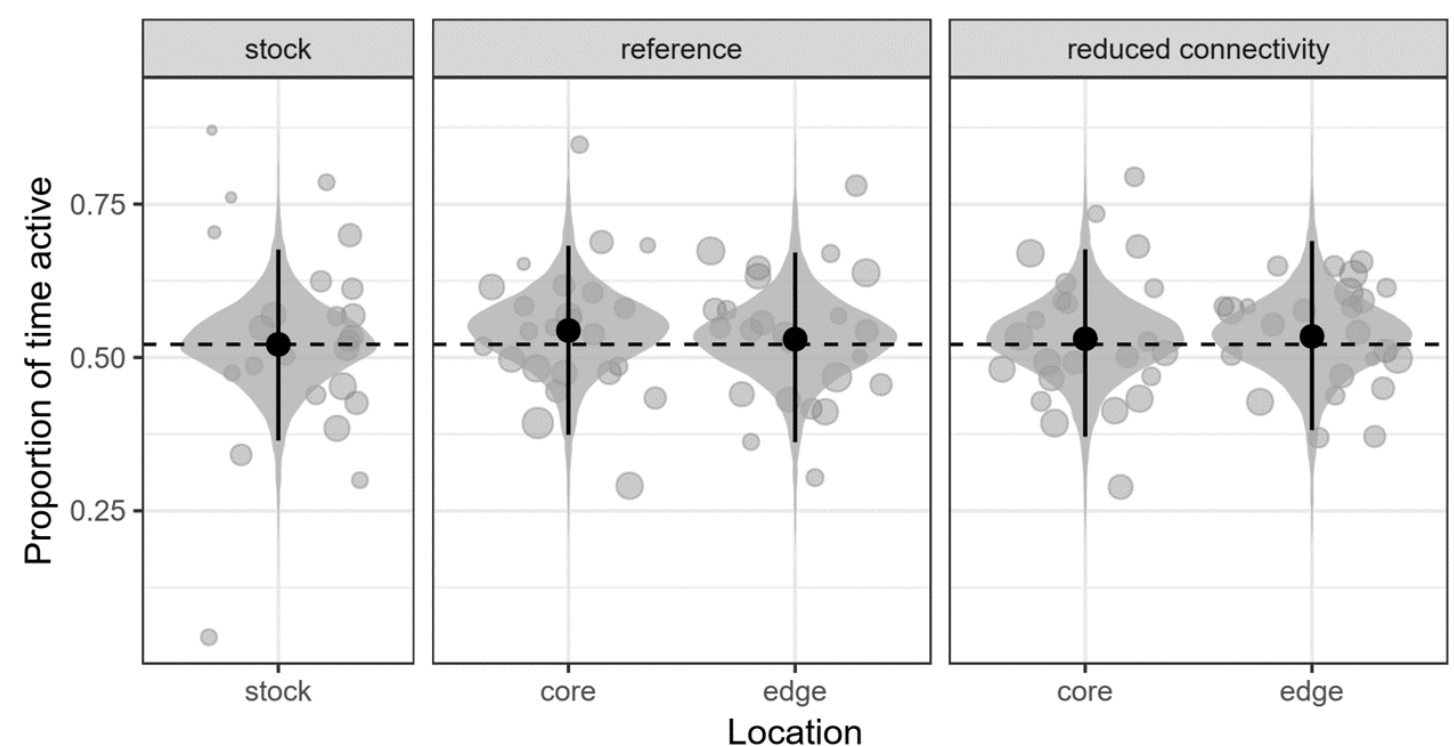

346 Figure 4. Posterior distributions of mean short-term activity, based on filmed movement tracks;

347 black dots and segments: posterior means and 95\% credible intervals. Grey dots: replicate-level

348 observed values; point size is proportional to the total valid observation time for a replicate 349 (sum of all movement bouts). The horizontal dashed line marks the posterior mean for the 350 stocks. See Supplementary Figure S.2.2 for posterior pairwise comparisons.

351 We found no consistent deviations from stock population dispersal in the first dispersal 352 experiment, as posteriors were wide (Fig. 5A). Dispersal rates were nonetheless higher in edge 353 than core populations, but only in landscapes with reduced connectivity ( $\log ($ odds ratio) $=0.88$ 354 [0.32; 1.45], Fig. 5A, Supplementary Figure S.2.3). In the low-density part of the second 355 experiment, there is similarly no consistent evolution of dispersal away from stock population 356 rates (Fig. 5B). Similarly to the first experiment however, dispersal from edge populations was 357 higher than in core populations, but this time only in "reference" landscapes ( $\log ($ odds ratio) = $3581.16[0.14 ; 2.19]$, Fig. 5B, Supplementary Figure S.2.4).

359 Stock populations exhibited positive density-dependent dispersal (log(odds ratio) = 0.91 [0.54;

360 1.28], Fig. 5C). After experimental evolution, this pattern was reversed, leading to negative 361 density-dependent dispersal, in two cases: in wasps coming from edge populations of 362 "reference" landscapes ( $\log ($ odds ratio) $=-1.57[-2.23 ;-0.90])$ and in wasps from core 363 populations of landscapes with reduced connectivity $(\log ($ odds ratio $)=-0.60[-1.06 ;-0.15])$ (Fig. 
bioRxiv preprint doi: https://doi.org/10.1101/2021.03.03.433752; this version posted August 23, 2021. The copyright holder for this preprint (which was not certified by peer review) is the author/funder, who has granted bioRxiv a license to display the preprint in perpetuity. It is made available under aCC-BY 4.0 International license.

364 5C). Dispersal remained positive density-dependent in the other two connectivity $\times$ location 365 treatments (Fig. 5C).

A
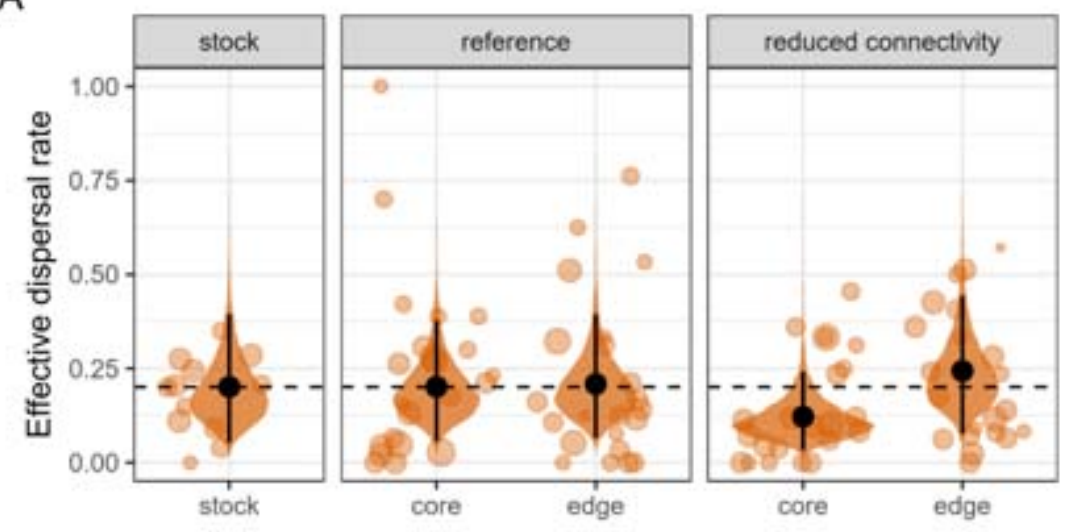

B

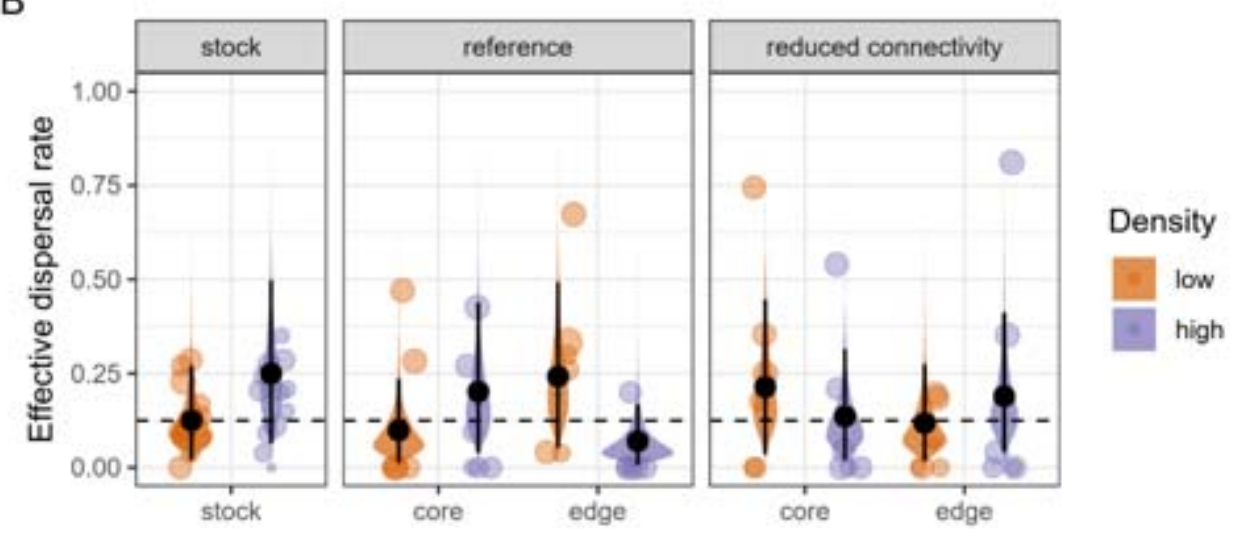

C

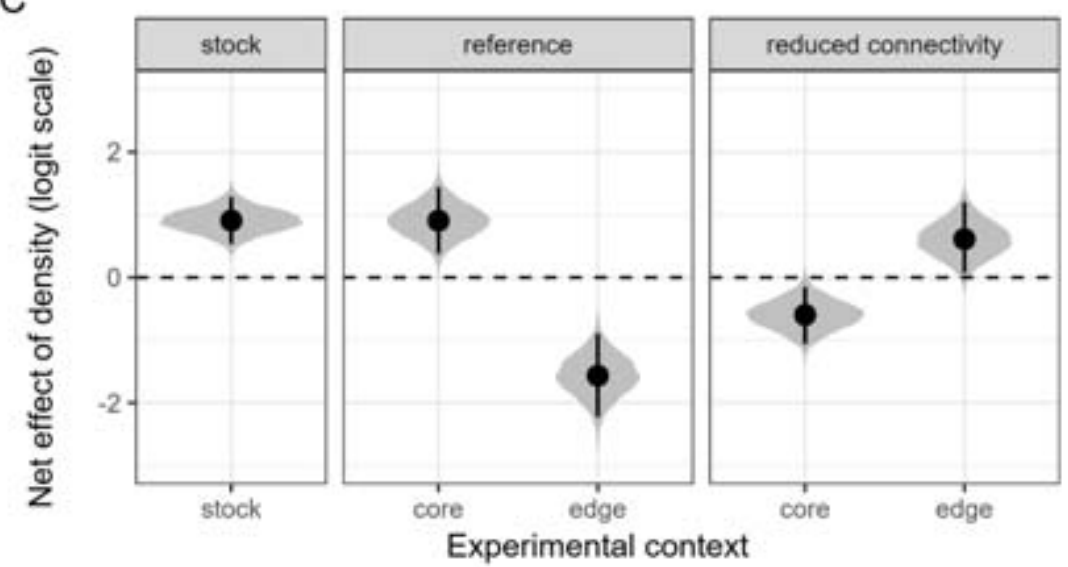


367 Figure 5. (A; B) Posterior distributions of mean effective dispersal rate, based on either the first 368 experiment $(A)$ or the second experiment (B; one generation later, with some wasps tested at 369 high density). The effect of total fecundity (see Methods) on posterior means is averaged out. 370 Black dots and segments: posterior means and 95\% credible intervals; the effect of total

371 fecundity (see Methods) on posterior predictions has been averaged out. Coloured dots are 372 observed values, dot size is proportional to total fecundity in each replicate (departure + arrival 373 patches combined). The horizontal dashed lines mark the posterior (low-density) means for the 374 stocks. (C) Net effect of juvenile density on dispersal (difference between posterior mean 375 dispersal at high and low densities, expressed on the logit scale). The horizontal dashed line 376 marks the absence of density-dependence. See Supplementary Figures S.2.3 and S.2.4 for the 377 other posterior pairwise comparisons.

378 Regarding individual fecundity, we found no evidence that landscape connectivity or patch 379 location had any effect in the first fecundity experiment (Fig. 6A, Supplementary Figure S.2.5).

380 Similarly, when looking at low-density fecundity in the second (density-dependent) experiment, 381 most of the treatments are not different from each other (Fig. 6B, Supplementary Figure S.2.6).

382 The only exception was that low-density edge populations were less fecund than the 383 corresponding stock ( $\log ($ fold change) $=-0.29[-0.56 ;-0.02]$, Fig. 6B, Supplementary Figure

384 S.2.6). Moving to the effect of rearing density, fecundity was not different between low-density 385 and high-density stock populations (Fig. 6C); after experimental evolution however, individuals 386 from core populations were less fecund if they came from high-density than if they came from a 387 low-density background, independently of connectivity treatment (log(fold change) $=-0.33$ [$3880.74 ; 0.02]$ in reference landscapes, -0.35 [-0.61 -0.11] in landscapes with reduced connectivity, 389 Fig. 6C). There was no such density effect for individuals from edge populations (Fig. 6C). As a 390 consequence of the effects described above, when reared at high densities, wasps coming from 391 the experimental landscapes are in almost all cases less fecund than the corresponding stock 392 wasps (the exception being wasps from the expansion edge of "reduced connectivity" 393 landscapes; Fig. 6B, Supplementary Figure S.2.6). 
bioRxiv preprint doi: $h$ ttps://doi.org/10.1101/2021.03.03.433752; this version posted August 23,2021 . The copyright holder for this preprint (which was not certified by peer review) is the author/funder, who has granted bioRxiv a license to display the preprint in perpetuity. It is made available under aCC-BY 4.0 International license.

A
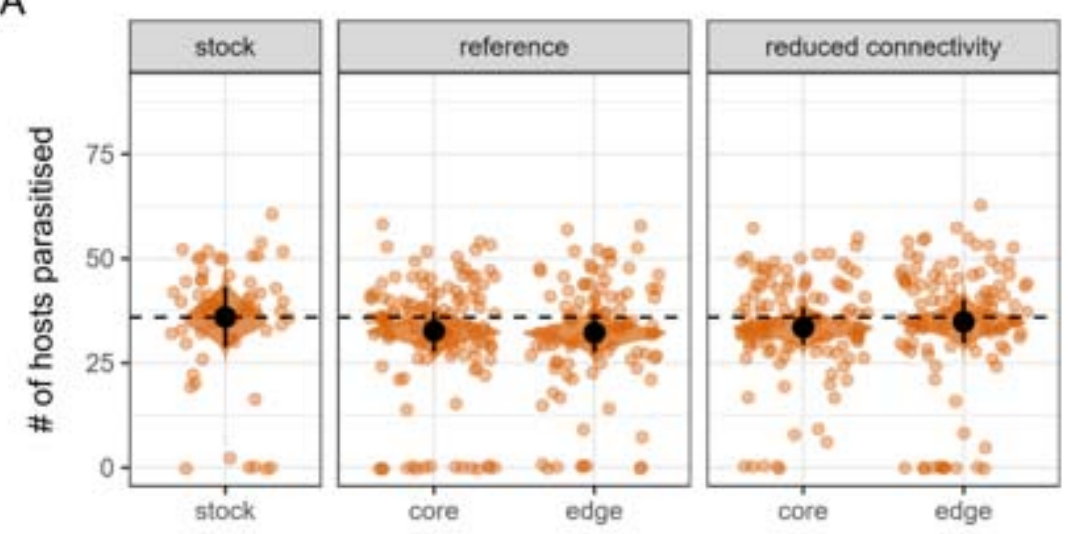

B

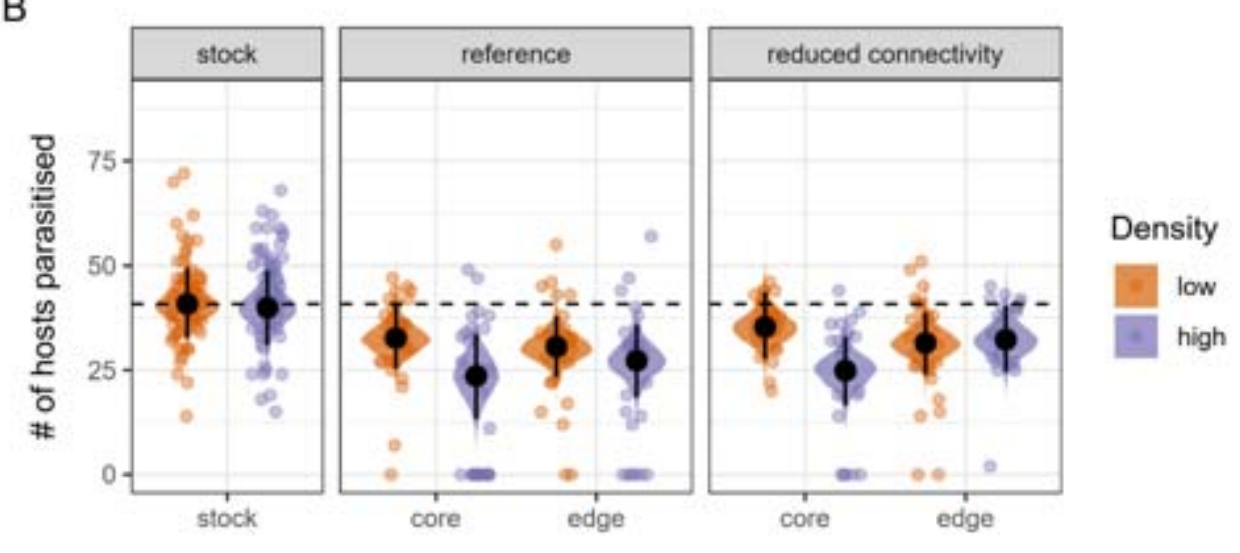

C
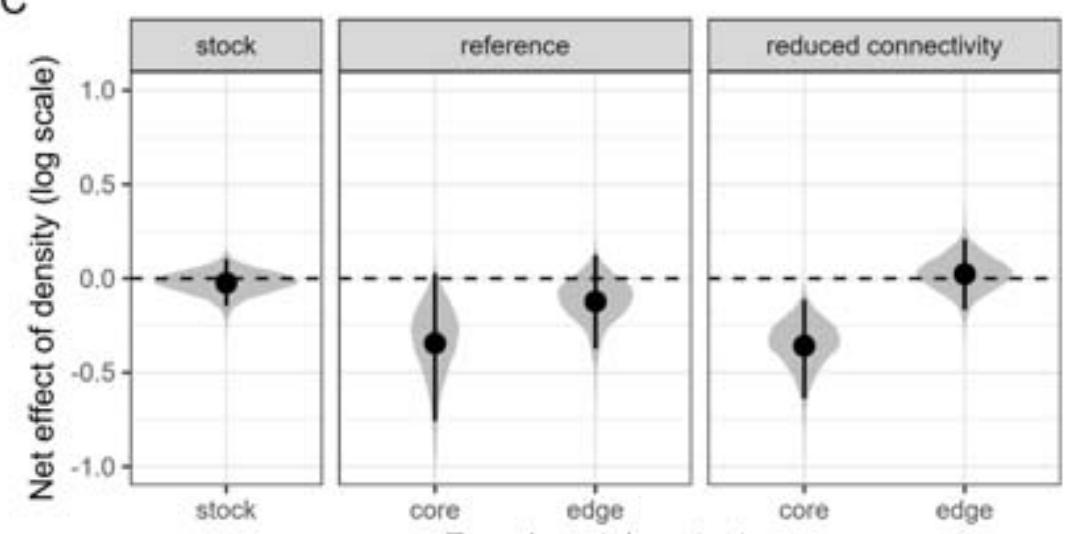

Experimental context

395 Figure 6. (A; B) Posterior distributions of mean per-capita fecundity, based on either the first experiment $(A)$ or the second experiment $(B$; one generation later, with some wasps tested at

397 high density). Black dots and segments: posterior means and 95\% credible intervals; coloured 398 dots: observed values. The horizontal dashed lines mark the posterior (low-density) means for 

fecundity at high and low densities, expressed on the log scale). The horizontal dashed line marks the absence of density-dependence. See Supplementary Figures S.2.5 and S.2.6 for the other posterior pairwise comparisons.

\section{Discussion}

404 We showed before that variation in landscape connectivity shapes the position of experimental 405 range expansions on the pushed/pulled expansion axis in Trichogramma wasps (Dahirel et al., 406 2021). We here find that these previously documented changes in expansion and neutral 407 diversity dynamics due to connectivity were not consistently accompanied by clear phenotypic 408 shifts at the range edge. However, we found some indications that the density-dependence of 409 dispersal, one of the two key parameters determining the pushed vs. pulled nature of 410 expansions (Birzu et al., 2019), may change during the range expansion process, and these 411 changes seemed to depend on the connectivity level.

412 We did not find any clear evidence for evolutionary changes in size or short-term activity, nor in 413 fecundity or effective dispersal when density-dependence was ignored (Figs 3 to 6). While 414 reproductive success did vary between treatments, it was only in the density-dependent 415 experiment, and the only consistent shift was that at high densities, post-experimental 416 evolution wasps were less fecund than wasps from stock populations (irrespective of

417 connectivity or patch location)(Fig. 6). We found some evidence of higher low-density dispersal 418 in edge compared to core populations, as expected from theory (Chuang \& Peterson, 2016; 419 Shine et al., 2011; Travis et al., 2009). However, our experiments are here inconsistent: low420 density dispersal was higher in edge vs. core patches only in "reduced connectivity" landscapes 421 in one dispersal experiment, and only in "reference" landscapes in the other dispersal 422 experiment (Fig. 5, Supplementary Figures S.2.3 and S.2.4). There was also no clear divergence 423 from the starting stock populations themselves (Fig. 5, Supplementary Figures S.2.3 and S.2.4). 424 Our results here contrast previous experiments (e.g. Williams, Kendall, et al., 2016) and 425 theoretical models (Williams, Snyder, et al., 2016) that showed both evolutionary changes in key 
426 traits along expansion edges, and that this evolution was accelerated in more fragmented 427 environments. While clear increases in average dispersal or per capita growth rates are often 428 expected at the edge of range expansions (Chuang \& Peterson, 2016; Fronhofer et al., 2017; 429 Phillips \& Perkins, 2019; Van Petegem et al., 2018; Weiss-Lehman et al., 2017), there are enough 430 exceptions to the "rule" (Chuang \& Peterson, 2016; Van Petegem et al., 2018; Wolz et al., 2020) 431 for these null/uncertain results not to be entirely surprising by themselves. Trade-offs among 432 traits may provide a mechanistic explanation for this absence of evolutionary response: 433 Williams et al. (2016) and Urquhart and Williams (2021) showed that the shape and strength of 434 the trade-offs among traits may influence whether the way these traits evolve during expansion 435 is sensitive to connectivity. Similarly, Ochocki et al. (2020) showed, using simulations, that 436 genetic trade-offs between dispersal and fecundity may reduce and in some cases prevent the 437 evolution of these traits at the range edge. As Ochocki et al. (2020) mentioned, knowledge 438 about trait architecture may matter a lot to interpret eco-evolutionary outcomes of range 439 expansion, and the variability among species/studies.

440 Whether or not trade-offs matter, focusing on trait(s) expression at only one density is limiting, 441 as the density-dependence of dispersal or growth actually plays a key role in shaping the 442 dynamics of range expansions (Birzu et al., 2019). We previously found that, in our 443 Trichogramma experimental system, expansions were more pushed when connectivity was 444 reduced, which means that connectivity influenced the density-dependence of growth and/or 445 dispersal, through plastic and/or evolved responses (Dahirel et al., 2021). While our data are 446 limited (see below), we here find some evidence for density-dependent effective dispersal and 447 reproductive success, and for variation in this density-dependence across landscape 448 connectivity contexts. Because we tested wasps using a common garden protocol, the 449 differences we observed are likely the result of evolutionary divergence during expansions 450 (although parental and grandparental effects on density-dependent dispersal cannot be ruled 451 out entirely; Bitume et al., 2014).

452 First, in core populations, the experiments led to the appearance of a link between density and 453 per capita fecundity that is absent from edge populations (as well as from stock populations). 454 Specifically, wasps coming from these core lineages had fewer offspring on average when raised 
455 in high-density conditions (Fig. 6). This lower fecundity is expected if there is an egg number-egg

456 size trade-off, as higher competition in core patches would favour larger, more competitive

457 larvae (Segoli \& Wajnberg, 2020). For instance, in Callosobruchus chinensis beetles parasitising

458 seeds, higher larval competition within seeds leads to adults producing both a reduced number

459 of eggs (Vamosi, 2005) and larger eggs (after accounting for emerging female size; Yanagi et al.,

460 2013). Alternatively, core populations may have evolved a higher propensity to superparasitism,

461 since there individuals experienced higher densities, and encounters with hosts parasitized by

462 other wasps, more frequently (Van Alphen \& Visser, 1990). Wasps emerging from

463 superparasitized hosts tend to be smaller and less fecund (Durocher-Granger et al., 2011). To

464 confirm and disentangle these hypotheses however, further experiments would be needed to

465 determine whether there actually is an egg number-egg size trade-off in our tested populations.

466 Second, Trichogramma wasps from the stock populations dispersed more on average if they 467 came from a high density background (Fig. 5). This finding fits with the classic view of density-

468 dependent dispersal as a response to increased competition (Bowler \& Benton, 2005; Harman

469 et al., 2020), and is a logical extension of previous results showing Trichogramma brassicae

470 wasps left host eggs patches earlier if more were already parasitized (Wajnberg et al., 2000).

471 The direction of this density-dispersal relationship was seemingly reversed in "reference" edge

472 populations after 12 generations of evolution and expansion (Fig. 5), with wasps dispersing

473 more from low-density populations. Our results here broadly agree with theory, which tends to

474 predict the loss of positive density-dependent dispersal at low-density expansion edges (cf e.g.

475 Travis et al., 2009). There is one key nuance in that theoretical models often predict 476 unconditional high dispersal over most of the range of densities as a result, where we found a

477 shift to negative density-dependent dispersal. It is difficult to say whether the former is the

478 "true" expected endpoint during range expansions, however, given many dispersal models are 479 designed or parameterized in a way that excludes the possibility of negative density-dependent 480 dispersal (e.g. Kun \& Scheuring, 2006; Poethke \& Hovestadt, 2002; Travis et al., 2009). Indeed, 481 other empirical studies show shifts to negative density-dependent dispersal can happen at the 482 edge of range expansions (Fronhofer et al., 2017; Simmons \& Thomas, 2004). In any case, the 
483 key result remains consistent with theory, in that evolution at the range edge removes the 484 positive density-dependence of dispersal that existed initially.

485 By contrast, when connectivity was reduced, no clear evolutionary changes in dispersal reaction 486 norm occurred at the range edge (Fig. 5): the slope remained positive, albeit slightly shallower 487 (as in Weiss-Lehman et al., 2017). Strong enough increases in dispersal costs (such as those that 488 may be caused by reduced connectivity) are predicted to favour more positive density489 dependent dispersal (Govindan et al., 2015; Rodrigues \& Johnstone, 2014; Travis et al., 1999): 490 our results at the expanding edge are here consistent with existing theory. In core populations 491 however, dispersal actually became negative density-dependent when connectivity was reduced 492 (Fig. 5), seemingly contradicting the previous argument. As discussed above, the theory 493 explaining negative density-dependent dispersal is much less developed in stable 494 metapopulations, let alone in range expansions. Among the few existing models, Rodrigues and 495 Johnstone (2014) predicted that, at least in a non-expanding context, reduced temporal 496 variability should favour negative density-dependent dispersal. Reusing population size data in 497 Dahirel et al. (2021), we find that reduced connectivity did indeed lead to lower temporal 498 variability in core patches (Supplementary Material S3). We can tentatively interpret our 499 results as the interplay of three "forces." On one side, the expansion process itself drives the 500 loss of positive density-dependent dispersal at the expansion edge. On the other side, 501 connectivity has dual and contradictory effects: the direct effects of reduced connectivity on 502 dispersal costs would favour positive density-dependent dispersal; while the indirect effects 503 through demographic stochasticity would favour negative density-dependent dispersal.

504 Taken altogether, our results confirm the importance of context-dependence when studying 505 dispersal (Bonte \& Dahirel, 2017; Matthysen, 2012). This is especially true for range expansions, 506 which are often associated with a core-to-edge density gradient. We argue that not considering 507 this context-dependence may explain (some of the) previous failures to detect trait evolution 508 during range expansions (see e.g. compilation in Chuang \& Peterson, 2016), and we recommend 509 testing for density-dependence whenever it is logistically possible (as in e.g. Weiss-Lehman et 510 al., 2017). 
511 We acknowledge that these findings regarding dispersal come from the experiment with the 512 lowest sample size within this study (see Methods and Fig. 2) and need further confirmation.

513 High numbers of replicate landscapes in experimental (and natural) expansion studies are 514 especially important if we want to make generalizable inferences and predictions, due to the 515 key role of evolutionary stochasticity in shaping outcomes (Phillips, 2015; Weiss-Lehman et al., 516 2017; Williams et al., 2019). Moreover, we only sampled a limited subset of this species genetic 517 diversity, and the three strains we work with may be biased towards some life histories; further 518 comparative analyses would be better equipped to determine the effect of initial 519 genetic/phenotypic variation on ecological and evolutionary dynamics during expansions (Miller 520 et al., 2020). Finally, the fact we only detected evolutionary changes in the density-dependent 521 experiment may be because we used, due again to limited sample size for some traits, a coarse 522 definition of "core" vs. "edge" patches that ignored variation in distances travelled since the 523 start of expansions/expansion speed. Despite these potential issues, our findings on the 524 evolution of density-dependent dispersal are fully consistent with previous results and 525 expectations regarding pushed vs. pulled expansions (Birzu et al., 2019; Dahirel et al., 2021), as 526 detailed below. As such, we see them as a first step towards research that better accounts for 527 the complexities of eco-evolutionary dynamics during (pushed) range expansions, and hope that 528 they encourage further studies on the subject.

\section{Conclusion: implications for the evolution of pushed expansions}

530 Although Trichogramma brassicae wasps start the experiments with positive density-dependent 531 dispersal, it seems edge populations evolve away from that strategy rapidly if left to expand in 532 relatively well connected "reference" landscapes (Fig. 6). Our experimental results agree with 533 Erm and Phillips (2020)'s model, in which evolution should lead initially pushed expansions to 534 become pulled (in their case with Allee effect-induced pushed expansions, in ours with density535 dependent dispersal). The fundamental mechanism is the same in both cases: low densities at 536 the expanding range edge mean that anything that disperses or grows worse at low densities 537 will be outperformed/outrun, leading to an accumulation of individuals that disperse/grow well 538 at low densities. Taken alone, these results would imply pushed range expansions are rare in 539 nature since evolution would tend to "erase" them, or at least not as common as would be 
540 expected from general frequencies of Allee effects (Gregory et al., 2010) and positive density541 dependent dispersal (Harman et al., 2020) in non-expanding populations. On the other hand, we

542 found that positive density-dependent dispersal is comparatively maintained in edge 543 populations, even after $>10$ generations of expansion, in landscapes with reduced connectivity.

544 Accordingly, these expansions were previously shown to have more "pushed" characteristics 545 than controls (Dahirel et al., 2021). Thus, persistent pushed expansions may actually be

546 favoured in the many landscapes experiencing anthropogenic connectivity loss (e.g. Horváth et

547 al., 2019). In any case, our results show that environmental conditions and constraints may be

548 key to the maintenance of pushed expansion dynamics in the face of evolutionary dynamics, 549 and that the context dependence of pushed expansions needs to be further explored. We note 550 however that more work (experimental or modelling) is needed to confirm this, especially to 551 understand the implications of our results on longer time scales (Birzu et al., 2019).

552 Pushed and pulled expansions can differ in (relative) speed, genetic diversity (Dahirel et al.,

553 2021) and, as our results show here, phenotypic composition. Lineages/individuals with

554 different dispersal strategies may also differ in traits influencing population stability (Jacob et

555 al., 2019) or ecosystem functioning (Cote et al., 2017; Little et al., 2019). Understanding what

556 environmental conditions favour or disfavour the evolutionary maintenance of "pushiness"

557 during expansions may help more generally to understand the evolution of many traits during 558 range expansions, and the possible functional effects of expanding species on ecosystems.

\section{Acknowledgements}

560 We thank participants to the 2019 conference of the British Ecological Society, as well as 561 Thomas Guillemaud, for their questions during talks and discussions leading up to this paper.

562 We also thank Inês Fragata and three anonymous reviewers for helpful comments on a previous 563 version of this paper. 


\section{Data availability}

565 Data and R scripts to reproduce all analyses presented in this manuscript are available on Github 566 (https://github.com/mdahirel/pushed-pulled-2020-phenotype) and archived in Zenodo (v1.2;

567 https://doi.org/10.5281/zenodo.4570235). Copies of Supplementary Materials are also available 568 from the same source.

\section{Funding}

570 This work was funded by the French Agence Nationale de la Recherche (TriPTIC, ANR-14-CE18571 0002; PushToiDeLa, ANR-18-CE32-0008).

\section{Conflict of interest disclosure}

573 The authors declare they have no financial conflict of interest in relation with the content of this 574 article. Four authors are recommenders for one or several Peer Communities (PCI Evol Biol: VC, 575 SF, EL, EV; PCI Ecology and PCI Zoology: VC, EL, EV).

\section{References}

Allan, C., Burel, J.-M., Moore, J., Blackburn, C., Linkert, M., Loynton, S., MacDonald, D., Moore, W. J., Neves, C., Patterson, A., Porter, M., Tarkowska, A., Loranger, B., Avondo, J., Lagerstedt, I., Lianas, L., Leo, S., Hands, K., Hay, R. T., ... Swedlow, J. R. (2012). OMERO: flexible, model-driven data management for experimental biology. Nature Methods, 9(3), $245-253$.

Allee, W. C., \& Bowen, E. S. (1932). Studies in animal aggregations: Mass protection against colloidal silver among goldfishes. Journal of Experimental Zoology, 61(2), 185-207. https://doi.org/10.1002/jez.1400610202 
586

587

588

589

590

591

592

593

594

595

596

597

598

599

600

601

602

603

604

605

606

607

608

609

610

611

Benhamou, S. (2004). How to reliably estimate the tortuosity of an animal's path. Journal of Theoretical Biology, 229(2), 209-220. https://doi.org/10.1016/j.jtbi.2004.03.016

Birzu, G., Hallatschek, O., \& Korolev, K. S. (2018). Fluctuations uncover a distinct class of traveling waves. Proceedings of the National Academy of Sciences, 115(16), E3645-E3654. https://doi.org/10.1073/pnas.1715737115

Birzu, G., Matin, S., Hallatschek, O., \& Korolev, K. S. (2019). Genetic drift in range expansions is very sensitive to density dependence in dispersal and growth. Ecology Letters, 22(11), 1817-1827. https://doi.org/10.1111/ele.13364

Bitume, E. V., Bonte, D., Ronce, O., Olivieri, I., \& Nieberding, C. M. (2014). Dispersal distance is influenced by parental and grand-parental density. Proceedings of the Royal Society of London B: Biological Sciences, 281(1790), 20141061. https://doi.org/10.1098/rspb.2014.1061

Bonte, D., \& Dahirel, M. (2017). Dispersal: a central and independent trait in life history. Oikos, 126(4), 472-479. https://doi.org/10.1111/oik.03801

Bowler, D. E., \& Benton, T. G. (2005). Causes and consequences of animal dispersal strategies: relating individual behaviour to spatial dynamics. Biological Reviews, 80(2), 205-225. https://doi.org/10.1017/S1464793104006645

Branson, K., Robie, A. A., Bender, J., Perona, P., \& Dickinson, M. H. (2009). High-throughput ethomics in large groups of Drosophila. Nature Methods, 6(6), 451-457. https://doi.org/10.1038/nmeth.1328

Burton, O. J., Phillips, B. L., \& Travis, J. M. J. (2010). Trade-offs and the evolution of life-histories during range expansion. Ecology Letters, 13(10), 1210-1220. https://doi.org/10.1111/j.14610248.2010.01505.x

Bürkner, P.-C. (2017). brms: an R package for Bayesian multilevel models using Stan. Journal of Statistical Software, 80(1), 1-28. https://doi.org/10.18637/jss.v080.i01

Carpenter, B., Gelman, A., Hoffman, M. D., Lee, D., Goodrich, B., Betancourt, M., Brubaker, M., Guo, J., Li, P., \& Riddell, A. (2017). Stan: a probabilistic programming language. Journal of Statistical Software, 76(1), 1-32. https://doi.org/10.18637/jss.v076.i01 
612 Chuang, A., \& Peterson, C. R. (2016). Expanding population edges: theories, traits, and trade-offs. Global Change Biology, 22(2), 494-512. https://doi.org/10.1111/gcb.13107

614 Clutton-Brock, T. H., \& Harvey, P. H. (1977). Primate ecology and social organization. Journal of Zoology, 183(1), 1-39. https://doi.org/10.1111/j.1469-7998.1977.tb04171.x

616 Corrigan, J. E., Laing, J. E., \& Zubricky, J. S. (1995). Effects of parasitoid to host ratio and time of day of 617 parasitism on development and emergence of Trichogramma minutum (Hymenoptera: Trichogrammatidae) parasitizing eggs of Ephestia kuehniella (Lepidoptera: Pyralidae). Annals of the

Cote, J., Brodin, T., Fogarty, S., \& Sih, A. (2017). Non-random dispersal mediates invader impacts on the invertebrate community. Journal of Animal Ecology, 86(6), 1298-1307. https://doi.org/10.1111/1365-2656.12734

623 Courchamp, F., Berec, L., \& Gascoigne, J. (2008). Allee effects in ecology and conservation. Oxford University Press.

625 Cwynar, L. C., \& MacDonald, G. M. (1987). Geographical variation of lodgepole pine in relation to 626 population history. The American Naturalist, 129(3), 463-469. https://doi.org/10.1086/284651

627 Dahirel, M., Bertin, A., Haond, M., Blin, A., Lombaert, E., Calcagno, V., Fellous, S., Mailleret, L., Malausa, 628 T., \& Vercken, E. (2021). Shifts from pulled to pushed range expansions caused by reduction of landscape connectivity. Oikos, oik.08278. https://doi.org/10.1111/oik.08278

630 Deforet, M., Carmona-Fontaine, C., Korolev, K. S., \& Xavier, J. B. (2019). Evolution at the edge of expanding populations. The American Naturalist, 194(3), 291-305. https://doi.org/10.1086/704594

Des Roches, S., Post, D. M., Turley, N. E., Bailey, J. K., Hendry, A. P., Kinnison, M. T., Schweitzer, J. A., \& Evolution, 2(1), 57-64. https://doi.org/10.1038/s41559-017-0402-5

636 Durocher-Granger, L., Martel, V., \& Boivin, G. (2011). Gamete number and size correlate with adult size 637 in the egg parasitoid Trichogramma euproctidis. Entomologia Experimentalis Et Applicata, 140(3), 638 262-268. https://doi.org/10.1111/j.1570-7458.2011.01158.x 
639 Erm, P., \& Phillips, B. L. (2020). Evolution transforms pushed waves into pulled waves. The American Naturalist, 195(3), E87-E99. https://doi.org/10.1086/707324

641 Fellous, S., Angot, G., Orsucci, M., Migeon, A., Auger, P., Olivieri, I., \& Navajas, M. (2014). Combining experimental evolution and field population assays to study the evolution of host range breadth. Journal of Evolutionary Biology, 27(5), 911-919. https://doi.org/10.1111/jeb.12362

Fronhofer, E. A., Gut, S., \& Altermatt, F. (2017). Evolution of density-dependent movement during

Fronhofer, E. A., Legrand, D., Altermatt, F., Ansart, A., Blanchet, S., Bonte, D., Chaine, A., Dahirel, M., Laender, F. D., Raedt, J. D., Gesu, L. di, Jacob, S., Kaltz, O., Laurent, E., Little, C. J., Madec, L., Manzi, F., Masier, S., Pellerin, F., ... Cote, J. (2018). Bottom-up and top-down control of dispersal across major organismal groups. Nature Ecology \& Evolution, 2(12), 1859-1863. https://doi.org/10.1038/s41559-018-0686-0

Gabry, J., Simpson, D., Vehtari, A., Betancourt, M., \& Gelman, A. (2019). Visualization in Bayesian workflow. Journal of the Royal Statistical Society: Series A (Statistics in Society), 182(2), 389-402. https://doi.org/10.1111/rssa.12378

Gandhi, S. R., Korolev, K. S., \& Gore, J. (2019). Cooperation mitigates diversity loss in a spatially expanding microbial population. Proceedings of the National Academy of Sciences, 116(47), 23582-23587. https://doi.org/10.1073/pnas.1910075116

Govindan, B. N., Feng, Z., DeWoody, Y. D., \& Swihart, R. K. (2015). Intermediate disturbance in experimental landscapes improves persistence of beetle metapopulations. Ecology, 96(3), 728736. https://doi.org/10.1890/14-0044.1

661 Gralka, M., \& Hallatschek, O. (2019). Environmental heterogeneity can tip the population genetics of range expansions. elife, 8, e44359. https://doi.org/10.7554/eLife.44359

663 Gregory, S. D., Bradshaw, C. J. A., Brook, B. W., \& Courchamp, F. (2010). Limited evidence for the demographic Allee effect from numerous species across taxa. Ecology, 91(7), 2151-2161. https://doi.org/10.1890/09-1128.1 
Hadfield, J. D., \& Nakagawa, S. (2010). General quantitative genetic methods for comparative biology: phylogenies, taxonomies and multi-trait models for continuous and categorical characters. Journal of Evolutionary Biology, 23(3), 494-508. https://doi.org/10.1111/j.1420-9101.2009.01915.x

Harman, R. R., Goddard, J., Shivaji, R., \& Cronin, J. T. (2020). Frequency of occurrence and population-

Horváth, Z., Ptacnik, R., Vad, C. F., \& Chase, J. M. (2019). Habitat loss over six decades accelerates regional and local biodiversity loss via changing landscape connectance. Ecology Letters, 22(6), 1019-1027. https://doi.org/https://doi.org/10.1111/ele.13260

Hunter, M., Krishnan, N., Liu, T., Möbius, W., \& Fusco, D. (2021). Virus-Host Interactions Shape Viral Dispersal Giving Rise to Distinct Classes of Traveling Waves in Spatial Expansions. Physical Review X, 11(2), 021066. https://doi.org/10.1103/PhysRevX.11.021066

Jacob, S., Chaine, A. S., Huet, M., Clobert, J., \& Legrand, D. (2019). Variability in dispersal syndromes is a key driver of metapopulation dynamics in experimental microcosms. The American Naturalist, 194(5), 613-626. https://doi.org/10.1086/705410

681 Kay, M. (2019). tidybayes: tidy data and geoms for Bayesian models. https://doi.org/10.5281/zenodo.1308151

683 Kun, Á., \& Scheuring, I. (2006). The evolution of density-dependent dispersal in a noisy spatial population model. Oikos, 115(2), 308-320. https://doi.org/10.1111/j.2006.0030-1299.15061.x

685 Lenoir, J., Bertrand, R., Comte, L., Bourgeaud, L., Hattab, T., Murienne, J., \& Grenouillet, G. (2020). Species better track climate warming in the oceans than on land. Nature Ecology \& Evolution. https://doi.org/10.1038/s41559-020-1198-2 International Publishing. https://doi.org/10.1007/978-3-319-32043-4

690 Little, C. J., Fronhofer, E. A., \& Altermatt, F. (2019). Dispersal syndromes can impact ecosystem 691 functioning in spatially structured freshwater populations. Biology Letters, 15(3), 20180865. https://doi.org/10.1098/rsbl.2018.0865 
693

Lutscher, F., \& Musgrave, J. A. (2017). Behavioral responses to resource heterogeneity can accelerate biological invasions. Ecology, 98(5), 1229-1238. https://www.jstor.org/stable/26165212

Matthysen, E. (2012). Multicausality of dispersal: a review. In J. Clobert, M. Baguette, T. G. Benton, \& J. M. Bullock (Eds.), Dispersal ecology and evolution (pp. 3-18). Oxford University Press.

Matthysen, E. (2005). Density-dependent dispersal in birds and mammals. Ecography, 28(3), 403-416. http://onlinelibrary.wiley.com/doi/10.1111/j.0906-7590.2005.04073.x/pdf

McElreath, R. (2020). Statistical rethinking: a Bayesian course with examples in R and Stan (2nd edition). Chapman and Hall/CRC.

McLean, D. J., \& Volponi, M. A. S. (2018). trajr: An R package for characterisation of animal trajectories. Ethology, 124(6), 440-448. https://doi.org/https://doi.org/10.1111/eth.12739

Merwin, A. C. (2019). Flight capacity increases then declines from the core to the margins of an invasive species' range. Biology Letters, 15(11), 20190496. https://doi.org/10.1098/rsbl.2019.0496

Miller, T. E. X., Angert, A. L., Brown, C. D., Lee-Yaw, J. A., Lewis, M., Lutscher, F., Marculis, N. G., Melbourne, B. A., Shaw, A. K., Szúcs, M., Tabares, O., Usui, T., Weiss-Lehman, C., \& Williams, J. L. (2020). Eco-evolutionary dynamics of range expansion. Ecology, n/a(n/a), e03139. https://doi.org/10.1002/ecy.3139

Mishra, A., Chakraborty, P. P., \& Dey, S. (2020). Dispersal evolution diminishes the negative density dependence in dispersal. Evolution, evo.14070. https://doi.org/10.1111/evo.14070

Morel-Journel, T., Girod, P., Mailleret, L., Auguste, A., Blin, A., \& Vercken, E. (2016). The highs and lows of dispersal: how connectivity and initial population size jointly shape establishment dynamics in discrete landscapes. Oikos, 125(6), 769-777. https://doi.org/10.1111/oik.02718

Ochocki, B. M., Saltz, J. B., \& Miller, T. E. X. (2020). Demography-dispersal trait correlations modify the eco-evolutionary dynamics of range expansion. The American Naturalist, 195(2), 231-246. https://doi.org/10.1086/706904

Pachepsky, E., \& Levine, Jonathan M. (2011). Density dependence slows invader spread in fragmented landscapes. The American Naturalist, 177(1), 18-28. https://doi.org/10.1086/657438 
719 Pedersen, T. L. (2019). patchwork: the composer of plots. https://CRAN.R720 project.org/package=patchwork

721 Perkins, T. A., Phillips, B. L., Baskett, M. L., \& Hastings, A. (2013). Evolution of dispersal and life history 722 interact to drive accelerating spread of an invasive species. Ecology Letters, 16(8), 1079-1087. https://doi.org/10.1111/ele.12136

724 Phillips, B. L. (2015). Evolutionary processes make invasion speed difficult to predict. Biological Invasions, 17(7), 1949-1960. https://doi.org/10.1007/s10530-015-0849-8

Phillips, B. L., \& Perkins, T. A. (2019). Spatial sorting as the spatial analogue of natural selection. Theoretical Ecology. https://doi.org/10.1007/s12080-019-0412-9

Poethke, H. J., \& Hovestadt, T. (2002). Evolution of density-and patch-size-dependent dispersal rates. Proceedings of the Royal Society of London B: Biological Sciences, 269(1491), 637-645. https://doi.org/10.1098/rspb.2001.1936

R Core Team. (2021). R: a language and environment for statistical computing (Version 4.0.4) [Computer software]. R Foundation for Statistical Computing. https://www.R-project.org/

Raffard, A., Santoul, F., Cucherousset, J., \& Blanchet, S. (2019). The community and ecosystem consequences of intraspecific diversity: a meta-analysis. Biological Reviews, 94(2), 648-661. https://doi.org/10.1111/brv.12472

Renault, D., Laparie, M., McCauley, S. J., \& Bonte, D. (2018). Environmental adaptations, ecological filtering, and dispersal central to insect invasions. Annual Review of Entomology, 63(1), 345-368. https://doi.org/10.1146/annurev-ento-020117-043315

Rodrigues, A. M. M., \& Johnstone, R. A. (2014). Evolution of positive and negative density-dependent dispersal. Proceedings of the Royal Society of London B: Biological Sciences, 281(1791), 20141226. https://doi.org/10.1098/rspb.2014.1226

742 Ronce, O., \& Clobert, J. (2012). Dispersal syndromes. In J. Clobert, M. Baguette, T. G. Benton, \& J. M. 743 Bullock (Eds.), Dispersal ecology and evolution (pp. 119-138). Oxford University Press. 
744 Roques, L., Garnier, J., Hamel, F., \& Klein, E. K. (2012). Allee effect promotes diversity in traveling waves of colonization. Proceedings of the National Academy of Sciences, 109(23), 8828-8833. https://doi.org/10.1073/pnas.1201695109

Schreiber, S. J., \& Beckman, N. G. (2020). Individual variation in dispersal and fecundity increases rates of

Segoli, M., \& Wajnberg, E. (2020). The combined effect of host and food availability on optimized parasitoid life-history traits based on a three-dimensional trade-off surface. Journal of Evolutionary Biology, 33(6), 850-857. https://doi.org/10.1111/jeb.13617

Shine, R., Brown, G. P., \& Phillips, B. L. (2011). An evolutionary process that assembles phenotypes 753 through space rather than through time. Proceedings of the National Academy of Sciences, 108(14), 5708-5711. https://doi.org/10.1073/pnas.1018989108

Sibly, R. M., \& Hone, J. (2002). Population growth rate and its determinants: an overview. Philosophical Transactions of the Royal Society of London. Series B: Biological Sciences, 357(1425), 1153-1170. https://doi.org/10.1098/rstb.2002.1117

Simmons, Adam D., \& Thomas, Chris D. (2004). Changes in dispersal during species' range expansions. The American Naturalist, 164(3), 378-395. https://doi.org/10.1086/423430

760 Stokes, A. N. (1976). On two types of moving front in quasilinear diffusion. Mathematical Biosciences, 31(3), 307-315. https://doi.org/10.1016/0025-5564(76)90087-0

762 St-Onge, M., Cormier, D., Todorova, S., \& Lucas, É. (2014). Comparison of Ephestia kuehniella eggs sterilization methods for Trichogramma rearing. Biological Control, 70, 73-77. https://doi.org/10.1016/j.biocontrol.2013.12.006

765 Travis, J. M., \& Dytham, C. (2002). Dispersal evolution during invasions. Evolutionary Ecology Research, 4(8), 1119-1129. http://www.evolutionary-ecology.com/abstracts/v04/1413.html

767 Travis, J. M. J., Murrell, D. J., \& Dytham, C. (1999). The evolution of density-dependent dispersal. 768 Proceedings of the Royal Society of London B: Biological Sciences, 266(1431), 1837-1842. 
770 Travis, J. M. J., Mustin, K., Benton, T. G., \& Dytham, C. (2009). Accelerating invasion rates result from the evolution of density-dependent dispersal. Journal of Theoretical Biology, 259(1), 151-158. https://doi.org/10.1016/j.jtbi.2009.03.008

Urquhart, C. A., \& Williams, J. L. (2021). Trait correlations and landscape fragmentation jointly alter expansion speed via evolution at the leading edge in simulated range expansions. Theoretical Ecology. https://doi.org/10.1007/s12080-021-00503-z

Vamosi, S. M. (2005). Interactive effects of larval host and competition on adult fitness: an experimental test with seed beetles (Coleoptera: Bruchidae). Functional Ecology, 19(5), 859-864. https://doi.org/https://doi.org/10.1111/j.1365-2435.2005.01029.x

Van Alphen, J. J. M., \& Visser, M. E. (1990). Superparasitism as an adaptive strategy for insect parasitoids. Annual Review of

of Entomology, 35(1), 59-79. https://doi.org/10.1146/annurev.en.35.010190.000423

Van Petegem, K., Moerman, F., Dahirel, M., Fronhofer, E. A., Vandegehuchte, M. L., Van Leeuwen, T., Wybouw, N., Stoks, R., \& Bonte, D. (2018). Kin competition accelerates experimental range expansion in an arthropod herbivore. Ecology Letters, 21(2), 225-234. https://doi.org/10.1111/ele.12887

Vehtari, A., Gelman, A., Simpson, D., Carpenter, B., \& Bürkner, P.-C. (2020). Rank-normalization, folding, and localization: an improved \widehat $\{R\}$ for assessing convergence of MCMC. Bayesian Analysis. https://doi.org/10.1214/20-BA1221

Violle, C., Enquist, B. J., McGill, B. J., Jiang, L., Albert, C. H., Hulshof, C., Jung, V., \& Messier, J. (2012). The return of the variance: intraspecific variability in community ecology. Trends in Ecology \& Evolution, 27(4), 244-252. https://doi.org/10.1016/j.tree.2011.11.014 Theorem: an experimental analysis and a simulation model. Behavioral Ecology, 11(6), 577-586. https://doi.org/10.1093/beheco/11.6.577 speed and variance in experimental range expansions. Nature Communications, 8, 14303. https://doi.org/10.1038/ncomms14303 
Wickham, H., Averick, M., Bryan, J., Chang, W., McGowan, L., François, R., Grolemund, G., Hayes, A., Henry, L., Hester, J., Kuhn, M., Pedersen, T., Miller, E., Bache, S., Müller, K., Ooms, J., Robinson, D., Seidel, D., Spinu, V., ... Yutani, H. (2019). Welcome to the Tidyverse. Journal of Open Source Software, 4(43), 1686. https://doi.org/10.21105/joss.01686

802

Williams, J. L., Hufbauer, R. A., \& Miller, T. E. X. (2019). How evolution modifies the variability of range expansion. Trends in Ecology

\& Evolution, 34(10),

903-913. https://doi.org/10.1016/j.tree.2019.05.012

Williams, J. L., Kendall, B. E., \& Levine, J. M. (2016). Rapid evolution accelerates plant population spread in fragmented experimental landscapes. Science, 353(6298), 482-485. https://doi.org/10.1126/science.aaf6268

808 Williams, J. L., \& Levine, Jonathan M. (2018). Experimental evidence that density dependence strongly influences plant invasions through fragmented landscapes. Ecology, 99(4), 876-884. https://doi.org/10.1002/ecy.2156

811 Williams, J. L., Snyder, R. E., \& Levine, J. M. (2016). The influence of evolution on population spread through patchy landscapes. The American Naturalist, 188(1), 15-26. https://doi.org/10.1086/686685

Wolz, M., Klockmann, M., Schmitz, T., Pekár, S., Bonte, D., \& Uhl, G. (2020). Dispersal and life-history traits in a spider with rapid range expansion. Movement Ecology, 8(1), 2. https://doi.org/10.1186/s40462-019-0182-4

817 Yanagi, S., Saeki, Y., \& Tuda, M. (2013). Adaptive egg size plasticity for larval competition and its limits in 818 the seed beetle Callosobruchus chinensis. Entomologia Experimentalis Et Applicata, 148(2), 182819 187. https://doi.org/10.1111/eea.12088 